\title{
Density functional studies of the electronic structure and adsorption at molybdenum oxide surfaces
}

\author{
K. Hermann ${ }^{\text {a,* }}$, M. Witko ${ }^{\text {b }}$ A. Michalak ${ }^{\mathrm{c}}$ \\ ${ }^{a}$ Fritz-Haber-Institut der MPG, Faradayweg 4-6, D-14195, Berlin, Germany \\ ${ }^{\mathrm{b}}$ Institute of Catalysis and Surface Chemistry, Polish Academy of Sciences, Niezapominajek, 30239, Cracow, Poland \\ ${ }^{\mathrm{c}}$ Department of Computational Methods in Chemistry, Faculty of Chemistry, Jagiellonian University, R. Ingardena 3, 30060, Cracow, Poland
}

\begin{abstract}
The electronic structure and bonding at different oxygen sites of $\mathrm{MoO}_{3}\left(\begin{array}{lll}0 & 1\end{array}\right)$ and $\left(\begin{array}{lll}1 & 0 & 0\end{array}\right)$ surfaces is reviewed on the basis of ab initio density functional theory (DFT-LCGTO) cluster calculations. The clusters are chosen as finite sections of the ideal $\mathrm{MoO}_{3}$ surface where cluster embedding is achieved by bond saturation with hydrogen terminator atoms yielding clusters up to $\mathrm{Mo}_{7} \mathrm{O}_{30} \mathrm{H}_{18}$. Resulting charge density distributions and binding properties are analyzed by populations, bond orders, and electrostatic potential maps. Interatomic binding at the surface is determined by both ionic and covalent contributions with a clear distinction between terminal oxygens and different bridging surface oxygens. Electronic differences between the $\mathrm{MoO}_{3}$ $\left(\begin{array}{lll}0 & 1 & 0\end{array}\right)$ and $\left(\begin{array}{lll}1 & 0 & 0\end{array}\right)$ surfaces are found to be mainly due to the different atom arrangement while local atom charging and binding properties seem surface independent. The electronic surface parameters influence the behavior and reactions of adsorbed molecules as will be shown for $\mathrm{H}, \mathrm{OH}$, and $\mathrm{C}_{3} \mathrm{H}_{5}$ adsorbates. (C) 1999 Elsevier Science B.V. All rights reserved.
\end{abstract}

Keywords: Molybdenum oxides; Binding; Adsorption; Reaction; Density functional theory; Cluster models

\section{Introduction}

Molybdenum oxides are of major scientific importance due to their complex chemical behavior. These oxides, prepared as pure substrates or as compounds including other transition metal oxides, can act as catalysts in many reactions of rather different type such as redox processes, acid-base processes (e.g. isomerization, polymerization), hydrogenation and dehydrogenation, selective oxidation, oxidative conversion [1]. In particular, molybdenum trioxide, $\mathrm{MoO}_{3}$, based materials become important as catalysts

\footnotetext{
*Corresponding author. Tel.: +49-30-84134812; fax: +49-3084134701; e-mail: hermann@fhi-berlin.mpg.de
}

in the selective oxidation of hydrocarbons due to their structural and electronic surface properties. In experiments the oxidation is found to involve several steps yielding different products as a function of the local surface geometry and elemental composition of the molybdenum compound [1]. In a first step an organic molecule is activated by hydrogen abstraction near oxygen surface sites and in subsequent steps oxygens (possibly from different sites) are inserted. The details of these processes depend on the specific surface orientation. As an example we mention the allyl to acrolein conversion in a surface reaction

$$
\begin{aligned}
& \text { propene }\left(\mathrm{CH}_{3}-\mathrm{CH}=\mathrm{CH}_{2}\right) \Rightarrow \operatorname{allyl}\left(\mathrm{CH}_{2}-\mathrm{CH}-\mathrm{CH}_{2}\right) \\
& \Rightarrow \operatorname{acrolein}\left(\mathrm{CH}_{2}=\mathrm{CH}-\mathrm{CHO}\right)
\end{aligned}
$$


which involves simultaneous hydrogen abstraction and oxygen insertion and is found to occur on $\mathrm{MoO}_{3}\left(\begin{array}{lll}0 & 1 & 0\end{array}\right)$ but not on $\left(\begin{array}{lll}1 & 0 & 0\end{array}\right)$ surfaces [1]. Experimental as well as theoretical details of these oxidation reactions are still under discussion [1-3] and a microscopic understanding of the underlying electronic structure and bonding properties at different surface oxygen sites is missing.

In the present theoretical study we examine the electronic structure and bonding near geometrically different surface oxygen sites for both $\left(\begin{array}{lll}0 & 1 & 0\end{array}\right)$ and $\left(\begin{array}{lll}1 & 0 & 0\end{array}\right)$ oriented ideal $\mathrm{MoO}_{3}$ surfaces [4,5]. Since oxygen binding can be considered as a local phenomenon the surface cluster approach becomes meaningful. Thus, environments about the surface oxygens can be represented reasonably by bond saturated surface clusters of different size. Electronic wave functions and derived properties such as local charging, bond character, or electrostatic potentials of the surface clusters are determined by ab initio density functional theory (DFT) calculations. The results show that the interatomic binding at the two $\mathrm{MoO}_{3}$ surfaces is determined by both ionic and covalent contributions with clear distinctions between terminal oxygens and the different bridging surface oxygens. Further, the difference in behavior between the $\left(\begin{array}{lll}0 & 1 & 0\end{array}\right)$ and $\left(\begin{array}{lll}1 & 0 & 0\end{array}\right)$ surface is found to be mainly due to the different atom arrangement while local atom charging and binding properties seem surface independent. The electronic structure at the $\mathrm{MoO}_{3}$ surfaces influences possible reactions involving adsorbed molecules as will be discussed for hydrogen adsorption [6], $\mathrm{OH}$ desorption [6], and initial steps in the surface catalyzed allyl to acrolein oxidation [5,7].

\section{Theoretical}

Molybdenum trioxide, $\mathrm{MoO}_{3}$, forms an ionic layer type orthorhombic crystal structure [8], where bilayers (described by $\left(\mathrm{MoO}_{3}\right)_{4}$ unit cells) lie parallel to the $\left(\begin{array}{lll}0 & 1 & 0\end{array}\right)$ netplane which represents the easy cleavage plane of the crystal, see Fig. 1. While the internal interaction between atoms within the bilayers is dominated by rather strong ionic and covalent bonding the bilayers couple via weak (van der Waals) polarization forces. The ideal $\left(\begin{array}{lll}0 & 1 & 0\end{array}\right)$ surface of $\mathrm{MoO}_{3}$ is characterized by a simple network of Mo and $\mathrm{O}$ ions where

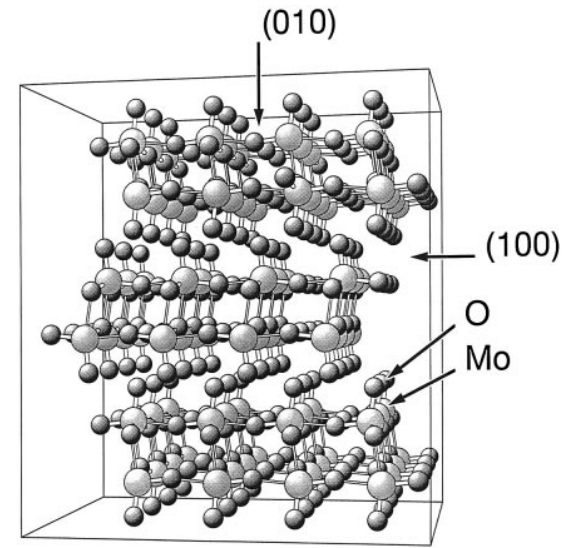

Fig. 1. Perspective view of the orthorhombic $\mathrm{MoO}_{3}$ crystal lattice. The $\left(\begin{array}{lll}0 & 1 & 0\end{array}\right)$ and $\left(\begin{array}{lll}1 & 0 & 0\end{array}\right)$ netplanes as well as the Mo and $\mathrm{O}$ centers are indicated.

there are basically three types of structurally different surface oxygen centers, see Fig. 2(a). First, terminal (molybdenyl) oxygens, denoted $\mathrm{O}(\mathrm{a})$, are coordinated to one Mo center directly below and cover all Mo ions at the surface. Second, asymmetrically bridging oxygens, denoted $\mathrm{O}(\mathrm{b})$, are coordinated to one Mo center and couple weakly with another surface Mo. Third, symmetrically bridging oxygens, $\mathrm{O}\left(\mathrm{b}^{\prime}\right)$, are coordinated to two Mo centers of the surface and couple weakly with a Mo center of the underlying sublayer. The ideal $\left(\begin{array}{lll}1 & 0 & 0\end{array}\right)$ surface of $\mathrm{MoO}_{3}$ is rather different in

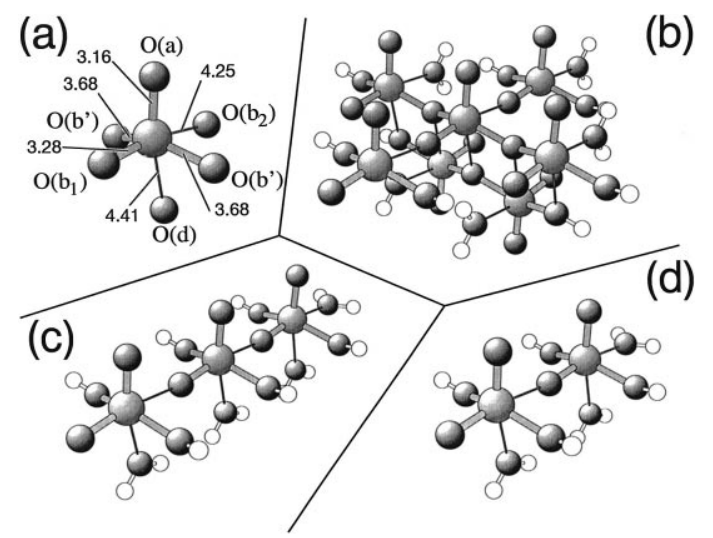

Fig. 2. Clusters used to model the $\mathrm{MoO}_{3}\left(\begin{array}{lll}0 & 1 & 0\end{array}\right)$ surface: (a) defines the inequivalent oxygen centers $\mathrm{O}((\mathrm{a})-(\mathrm{d}))$ and lists interatomic distances (in Bohr); ((b)-(d)) show the clusters $\mathrm{Mo}_{7} \mathrm{O}_{30} \mathrm{H}_{18}$, $\mathrm{Mo}_{3} \mathrm{O}_{16} \mathrm{H}_{14}$, and $\mathrm{Mo}_{2} \mathrm{O}_{11} \mathrm{H}_{10}$, where saturating hydrogens are sketched as small white spheres. 


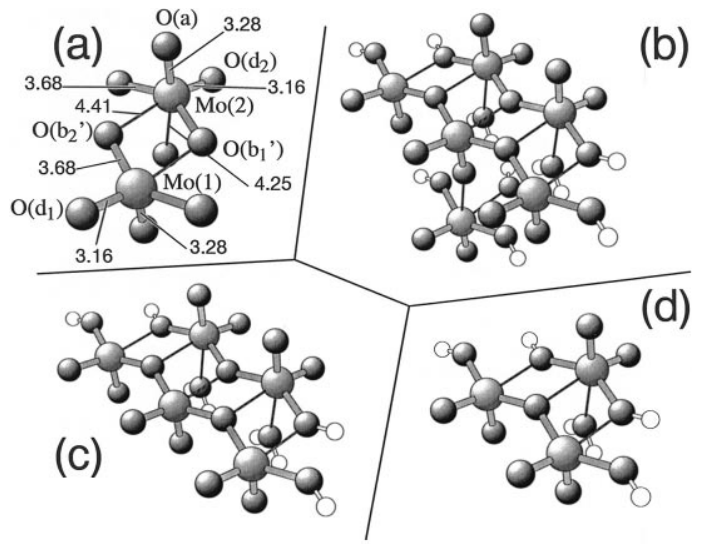

Fig. 3. Clusters used to model the $\mathrm{MoO}_{3}\left(\begin{array}{lll}1 & 0 & 0\end{array}\right)$ surface: (a) defines the inequivalent oxygen centers $\mathrm{O}((\mathrm{a})-(\mathrm{d}))$ about the two central molybdenums $\mathrm{Mo}(1)$ and $\mathrm{Mo}(2)$ and lists interatomic distances (in Bohr); ((b)-(d)) show the clusters $\mathrm{Mo}_{6} \mathrm{O}_{24} \mathrm{H}_{12}, \mathrm{Mo}_{5} \mathrm{O}_{19} \mathrm{H}_{8}$, and $\mathrm{Mo}_{3} \mathrm{O}_{12} \mathrm{H}_{6}$.

its structure from the $\left(\begin{array}{lll}0 & 1 & 0\end{array}\right)$ surface, see Fig. 1. This surface is much less compact and there are many structurally different metal as well as oxygen sites, see Fig. 3(a). Molybdenyl oxygens, O(a), are similar to those of the $\left(\begin{array}{lll}0 & 1 & 0\end{array}\right)$ surface and coordinated to one Mo center. However, they do not cover all Mo ions leaving bare metal sites at the $\left(\begin{array}{lll}1 & 0 & 0\end{array}\right)$ surface. Symmetrically bridging oxygens, $\mathrm{O}\left(\mathrm{b}_{1}^{\prime}{ }_{1}\right)$ and $\mathrm{O}\left(\mathrm{b}^{\prime}{ }_{2}\right)$, correspond structurally to $\mathrm{O}\left(\mathrm{b}^{\prime}\right)$ atoms of the $\left(\begin{array}{lll}0 & 1 & 0\end{array}\right)$ surface. They are coordinated to two Mo centers of the surface and couple weakly with a third Mo surface center. Finally, oxygens $\mathrm{O}\left(\mathrm{d}_{1}\right)$ and $\mathrm{O}\left(\mathrm{d}_{2}\right)$ correspond structurally to terminal molybdenyl oxygens of the ( $\left.\begin{array}{lll}0 & 1 & 0\end{array}\right)$ surface. They lie close to the plane of the surface molybdenums and are coordinated to one Mo center.

The $\mathrm{MoO}_{3}$ crystal structure determines the geometry of local model clusters for surface studies. The $\mathrm{MoO}_{3}\left(\begin{array}{lll}0 & 1 & 0\end{array}\right)$ surface is represented in the present work by different clusters, shown in Fig. 2, where the largest cluster, $\mathrm{Mo}_{7} \mathrm{O}_{30} \mathrm{H}_{18}$ (Fig. 2(b)), forms a symmetric surface section about a molybdenyl unit such that at least one member of each of the structurally different surface oxygens, $\mathrm{O}(\mathrm{a}), \mathrm{O}(\mathrm{b})$, and $\mathrm{O}\left(\mathrm{b}^{\prime}\right)$ occurs and experiences its full nearest neighbor environment within the cluster. In addition, peripheral oxygens are electronically saturated by hydrogen atoms. The $\mathrm{MoO}_{3}\left(\begin{array}{lll}1 & 0 & 0\end{array}\right)$ surface is approximated by clusters shown in Fig. 3. Here the largest cluster, $\mathrm{Mo}_{6} \mathrm{O}_{24} \mathrm{H}_{12}$ (Fig. 3(b)), yields also a characteristic surface unit containing each of the structurally different surface oxygens, $\mathrm{O}(\mathrm{a}), \mathrm{O}\left(\mathrm{b}^{\prime}\right)$, and $\mathrm{O}(\mathrm{d})$, with hydrogens serving as bond saturators at the cluster periphery. All surface clusters are chosen as finite sections of the ideal unreconstructed $\mathrm{MoO}_{3}\left(\begin{array}{lll}0 & 1 & 0\end{array}\right)$ and $\left(\begin{array}{lll}1 & 0 & 0\end{array}\right)$ surfaces, respectively, which assumes that these surfaces do not exhibit major reconstruction as suggested from the experiment $[1,9]$.

The electronic wave functions and derived properties of the clusters are determined by the $a b$ initio density functional theory (DFT) method [10], using linear combinations of atomic orbitals (LCGTO) with flexible basis sets of contracted Gaussians. The basis sets are taken from atom optimizations and are allelectron type for all oxygen and hydrogen centers, while molybdenum centers are represented by valence basis sets with their $[\mathrm{Ar}] 3 \mathrm{~d}^{10}$ cores described by model core potentials. In the calculations the program package DeMon ${ }^{1}$ was applied using the local spin density approximation (LSDA) as well as generalized gradient schemes (GGA) for exchange and correlation. For further details see Ref. [4].

\section{Results and discussion}

\section{1. $\mathrm{MoO}_{3}\left(\begin{array}{lll}0 & 1 & 0\end{array}\right)$ and (l 100$)$ substrate}

The calculated values of atomic charges from Mulliken population analyses and of Mayer bond orders for the clusters modeling the $\mathrm{MoO}_{3}\left(\begin{array}{lll}0 & 1 & 0\end{array}\right)$ and $\left(\begin{array}{lll}1 & 0 & 0\end{array}\right)$ surfaces are listed in Tables 1 and 2, respectively. As an important result from the calculations one finds only small variations between the different size clusters for a given surface orientation. Amongst the (010) surface clusters, the largest changes, $0.2 \mathrm{e}$, occur for the symmetrically bridging oxygens, $\mathrm{O}\left(\mathrm{b}^{\prime}\right)$, and for the nearby molybdenums in going from the two smaller to the largest cluster, $\mathrm{Mo}_{7} \mathrm{O}_{30} \mathrm{H}_{18}$, cp. Table 1. This can be understood by the fact that in $\mathrm{Mo}_{7} \mathrm{O}_{30} \mathrm{H}_{18}$ the $\mathrm{O}\left(\mathrm{b}^{\prime}\right)$ centers experience their natural Mo neighbors, see Fig. 2, whereas in the smaller clusters one of the two metal atoms is simulated by a hydrogen terminator.

\footnotetext{
${ }^{1}$ The DFT-LCGTO-program package DeMon was developed by A. St-Amant, D. Salahub at the University of Montreal.
} 
Table 1

Atomic charges and bond orders for $\mathrm{Mo}_{7} \mathrm{O}_{30} \mathrm{H}_{18}, \mathrm{Mo}_{3} \mathrm{O}_{16} \mathrm{H}_{14}$, $\mathrm{Mo}_{2} \mathrm{O}_{11} \mathrm{H}_{10}$, and $\mathrm{Mo}_{2} \mathrm{O}_{11} \mathrm{H}_{13}$ clusters representing the $\mathrm{MoO}_{3}\left(\begin{array}{lll}0 & 1 & 0\end{array}\right)$ surface

\begin{tabular}{llll}
\hline & $\mathrm{Mo}_{7} \mathrm{O}_{30} \mathrm{H}_{18}$ & $\mathrm{Mo}_{3} \mathrm{O}_{16} \mathrm{H}_{14}$ & $\mathrm{Mo}_{2} \mathrm{O}_{11} \mathrm{H}_{10}$ \\
\hline (a) Charges $q$ & & & \\
Mo & +1.67 & +1.43 & +1.43 \\
$\mathrm{O}(\mathrm{a})$ & -0.39 & -0.40 & -0.43 \\
$\mathrm{O}(\mathrm{b})$ & -0.54 & -0.55 & -0.54 \\
$\mathrm{O}\left(\mathrm{b}^{\prime}\right)$ & -0.84 & -0.76 & -0.77 \\
$\mathrm{O}(\mathrm{d})$ & -0.84 & -0.81 & -0.81 \\
& & & \\
(b) Bond orders & & & \\
$\mathrm{Mo-O}(\mathrm{a})$ & 1.93 & 1.97 & 1.95 \\
$\mathrm{Mo}-\mathrm{O}\left(\mathrm{b}_{1}\right)$ & 1.50 & 1.58 & 1.58 \\
$\mathrm{Mo}-\mathrm{O}\left(\mathrm{b}_{2}\right)$ & 0.20 & 0.21 & 0.16 \\
$\mathrm{Mo}-\mathrm{O}\left(\mathrm{b}^{\prime}\right)$ & 0.66 & 0.92 & 0.87 \\
$\mathrm{Mo}-\mathrm{O}(\mathrm{d})$ & 0.19 & 0.20 & 0.20 \\
\hline
\end{tabular}

The charges $q$ and bond orders $P$ involving molybdenum refer to the central Mo centers of the clusters.

Table 2

Atomic charges and bond orders for $\mathrm{Mo}_{6} \mathrm{O}_{24} \mathrm{H}_{12}, \mathrm{Mo}_{5} \mathrm{O}_{19} \mathrm{H}_{8}$, and $\mathrm{Mo}_{3} \mathrm{O}_{12} \mathrm{H}_{6}$ clusters representing the $\mathrm{MoO}_{3}\left(\begin{array}{lll}1 & 0 & 0\end{array}\right)$ surface

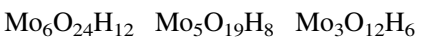

(a) Charges $q$

\begin{tabular}{|c|c|c|c|}
\hline $\operatorname{Mo}(1)$ & +1.63 & +1.48 & +1.41 \\
\hline $\operatorname{Mo}(2)$ & +1.62 & +1.63 & +1.62 \\
\hline $\mathrm{O}(\mathrm{a})\left[\cong \mathrm{O}\left(\mathrm{b}_{1}\right)\right.$ on $\left.\left(\begin{array}{lll}0 & 1 & 0\end{array}\right)\right]$ & -0.39 & -0.39 & -0.40 \\
\hline $\mathrm{O}\left(\mathrm{d}_{1}\right)\left[\cong \mathrm{O}(\mathrm{a})\right.$ on $\left.\left(\begin{array}{lll}0 & 1 & 0\end{array}\right)\right]$ & -0.37 & -0.38 & -0.39 \\
\hline $\mathrm{O}\left(\mathrm{d}_{2}\right)\left[\cong \mathrm{O}(\mathrm{a})\right.$ on $\left.\left(\begin{array}{lll}0 & 1 & 0\end{array}\right)\right]$ & -0.40 & -0.40 & -0.39 \\
\hline $\mathrm{O}\left(\mathrm{b}^{\prime}{ }_{1}\right)\left[\cong \mathrm{O}\left(\mathrm{b}^{\prime}\right)\right.$ on $\left.\left(\begin{array}{lll}0 & 1 & 0\end{array}\right)\right]$ & -0.88 & -0.88 & -0.86 \\
\hline $\mathrm{O}\left(\mathrm{b}_{2}^{\prime}\right)\left[\cong \mathrm{O}\left(\mathrm{b}^{\prime}\right)\right.$ on $\left.\left(\begin{array}{lll}0 & 1 & 0\end{array}\right)\right]$ & -0.83 & -0.85 & -0.85 \\
\hline
\end{tabular}

(b) Bond orders $P$

$\begin{array}{llll}\mathrm{Mo}(1)-\mathrm{O}\left(\mathrm{d}_{1}\right) & 1.95 & 1.95 & 1.96 \\ \mathrm{Mo}(1)-\mathrm{O}\left(\mathrm{b}^{\prime}{ }_{1}\right) & 0.23 & 0.22 & 0.26 \\ \mathrm{Mo}(1)-\mathrm{O}\left(\mathrm{b}^{\prime}{ }_{2}\right) & 0.66 & 0.64 & 0.59 \\ \mathrm{Mo}(2)-\mathrm{O}(\mathrm{a}) & 1.94 & 1.96 & 1.96 \\ \mathrm{Mo}(2)-\mathrm{O}\left(\mathrm{d}_{2}\right) & 1.95 & 1.96 & 2.00 \\ \mathrm{Mo}(2)-\mathrm{O}\left(\mathrm{b}^{\prime}{ }_{1}\right) & 0.55 & 0.55 & 0.57 \\ \mathrm{Mo}(2)-\mathrm{O}\left(\mathrm{b}^{\prime}{ }_{2}\right) & 0.19 & 0.18 & 0.20\end{array}$

The charges $q$ and bond orders $P$ involving molybdenum refer to the two inequivalent centers of the clusters, $\operatorname{Mo}(1)$ and $\operatorname{Mo}(2)$.

Therefore, the results of the largest cluster should be somewhat more reliable. Altogether, the charge differences between equivalent atoms of the different clusters are always small considering the uncertainties involved in calculating atom charges from populations which demonstrates that the surface cluster approach is reasonable for the present system.

The population analyses confirm the ionic nature of the $\mathrm{MoO}_{3}$ compound as suggested by basic chemical intuition. However, the actual ionic charging is found to be smaller than expected which suggests sizable covalent contributions to the interatomic binding in the clusters. The Mo metal centers become positively charged and are described by the populations as $\mathrm{Mo}^{+x}$ ions with $x=1.3-1.7$ while terminal oxygens $\mathrm{O}(\mathrm{a})$ are described as $\mathrm{O}^{-0.4}$, asymmetric bridging oxygens $\mathrm{O}(\mathrm{b})$ as $\mathrm{O}^{-0.6}$, and symmetric bridging oxygens $\mathrm{O}\left(\mathrm{b}^{\prime}\right)$ as $\mathrm{O}^{-0.8}$. Altogether, the oxygen centers of the $\mathrm{MoO}_{3}\left(\begin{array}{lll}1 & 0 & 0\end{array}\right)$ based clusters differ in their populations very little from those of the $\mathrm{MoO}_{3}(010)$ based clusters if structurally equivalent centers are compared. This suggests that charging of the atom centers is determined by the bulk structure rather than by the specific orientation of the ideal surface.

Results from bond order analyses give further information about interatomic binding at the $\mathrm{MoO}_{3}$ surfaces. The Mo-O(a) bond order indices involving terminal oxygens yield values 1.93-2.00 which describes a molybdenyl double bond. The asymmetric bridging oxygens $\mathrm{O}(\mathrm{b})$ yield $\mathrm{Mo}-\mathrm{O}$ bond orders that are quite different for the two Mo centers being bridged. For Mo closest to the oxygen, values of 1.5-1.6 show strong binding while for Mo further away bond orders of 0.2 suggest only small coupling. This confirms that the oxygens $\mathrm{O}(\mathrm{b})$ are coordinated mainly to one molybdenum center, and therefore, resemble the terminal molybdenyl oxygens $\mathrm{O}(\mathrm{a})$ which may be expected already from simple geometric considerations. Oxygens $\mathrm{O}\left(\mathrm{b}^{\prime}\right)$ bridging two Mo centers symmetrically result in Mo-O bond orders of $0.7-0.9$ which reflects Mo-O single bonds with each of the neighboring molybdenums.

The different types of bonding for different surface oxygens become also obvious by an inspection of the charge rearrangement due to bond formation as evidenced in respective charge density difference, $\Delta \rho(\mathbf{r})$, maps which are shown elsewhere [4]. Further, electrostatic potentials $V(\mathbf{r})$ computed from the cluster charge distributions [4] can give information about local charging and binding at the surface. Results of the electrostatic potential $V(z)$ above different oxygen sites on the $\mathrm{MoO}_{3}\left(\begin{array}{lll}0 & 1 & 0\end{array}\right)$ and (1 $\left.00 \begin{array}{ll}1 & 0\end{array}\right)$ surfaces, simulated by clusters $\mathrm{Mo}_{2} \mathrm{O}_{11} \mathrm{H}_{10}$ and $\mathrm{Mo}_{3} \mathrm{O}_{12} \mathrm{H}_{6}$, respec- 

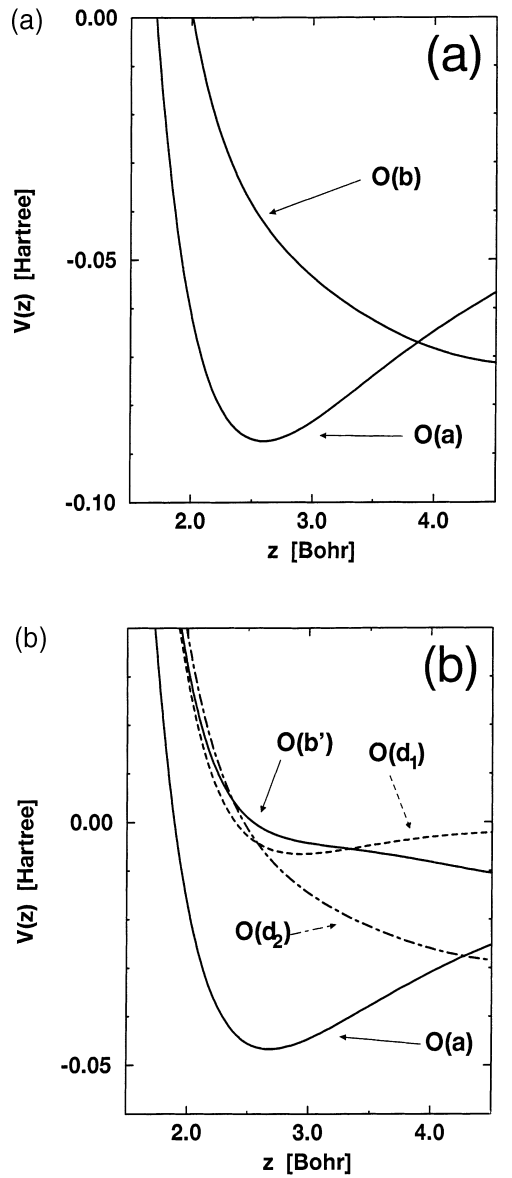

Fig. 4. Electrostatic potential $V(z)$ above inequivalent oxygen sites on the $\left(\begin{array}{lll}0 & 10\end{array}\right)$ and $\left(\begin{array}{lll}1 & 0 & 0\end{array}\right)$ surfaces of $\mathrm{MoO}_{3}$ (Fig. 4(a) and (b)) with $z$ denoting the perpendicular distance from the respective oxygen center, see text.

tively, are shown in Fig. 4. The calculations yield $V(z)$ always negative for typical molecular reaction distances above the $\left(\begin{array}{lll}0 & 1 & 0\end{array}\right)$ surface, see Fig. 4(a). This reflects the negative charge accumulation above the surface oxygens. In addition, there is a broad negative minimum above the terminal oxygen sites $\mathrm{O}$ (a) which suggests that electrophilic adparticles, like $\mathrm{H}^{+}$resulting from surface reactions, will be attracted preferentially at these sites and may form local surface bonds. On the $\left(\begin{array}{lll}1 & 0 & 0\end{array}\right)$ surface there are also electrostatic potential minima above the terminal $\mathrm{O}(\mathrm{a})$ centers whereas $V(\underline{r})$ is found always positive above Mo centers at the $\left(\begin{array}{lll}1 & 0 & 0\end{array}\right)$ surface. This suggests that direct bonding between $\mathrm{H}^{+}$and Mo ions (resulting even- tually in bronze type material) will not occur. Moreover, the presence of bare metal centers at the $\mathrm{MoO}_{3}\left(\begin{array}{lll}1 & 0 & 0\end{array}\right)$ surface leads to electrostatic potentials above $\mathrm{O}\left(\mathrm{b}^{\prime}\right)$ and $\mathrm{O}\left(\mathrm{d}_{1}\right)$ oxygen neighbors which are less negative then those above the bridging oxygens on the $\left(\begin{array}{lll}0 & 1 & 0\end{array}\right)$ surface, see Fig. 4(b).

\subsection{Hydrogen adsorption and $\mathrm{OH}$ desorption at $\mathrm{MoO}_{3}\left(\begin{array}{lll}0 & 1 & 0\end{array}\right)$}

Bond formation of hydrogen or $\mathrm{H}^{+}$approaching $\mathrm{MoO}_{3}\left(\begin{array}{lll}0 & 1 & 0\end{array}\right)$ and $\left(\begin{array}{lll}1 & 0 & 0\end{array}\right)$ at different surface oxygen sites is studied in total energy calculations on respective $\left(\mathrm{Mo}_{n} \mathrm{O}_{m} \mathrm{H}_{k}+\mathrm{H}\right)$ clusters [6]. The potential energy curves $E_{\text {tot }}(z)$ for $\mathrm{H}^{+}$adsorption and subsequent $\mathrm{OH}$ desorption at the $\mathrm{MoO}_{3}\left(\begin{array}{lll}0 & 1 & 0\end{array}\right)$ and $\left(\begin{array}{lll}1 & 0 & 0\end{array}\right)$ surfaces are shown in Figs. 5 and 6 , respectively. Here $z(\mathrm{O}-\mathrm{H})$ denotes the perpendicular distance between the adsorbing $\mathrm{H}^{+}$and the respective surface oxygen center while $z(\mathrm{Sub}-\mathrm{OH})$ represents the shift of the abstracted oxygen center of the desorbing $\mathrm{OH}$ from its initial surface position. The results of Fig. 5 are obtained with the electron exchange and correlation interaction accounted for by both the local spin density (LSDA) and the generalized gradient (GGA) approximation. Comparison shows a very close similarity between the

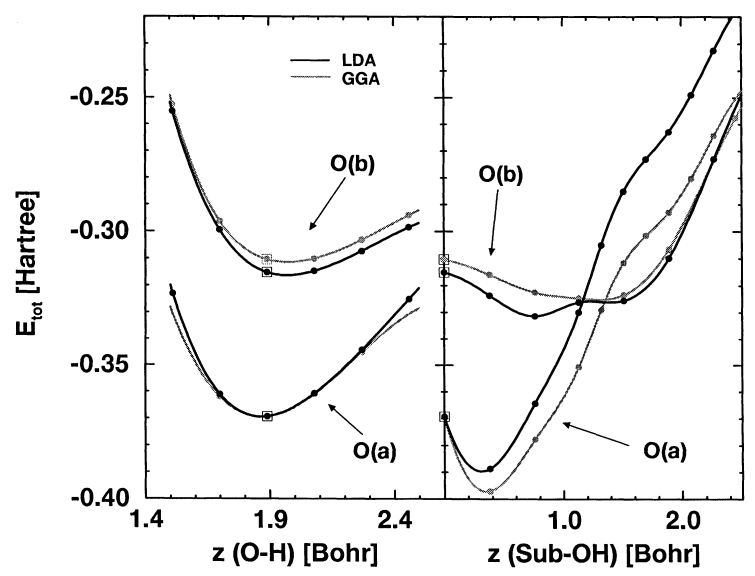

Fig. 5. Total energies $E_{\mathrm{tot}}(z)$ as a function of the adsorbate distances $z$ for $\mathrm{H}^{+}$adsorption (left) and the $\mathrm{OH}$ desorption (right) at the $\mathrm{MoO}_{3}\left(\begin{array}{lll}0 & 1 & 0\end{array}\right)$ surface represented by the $\mathrm{Mo}_{2} \mathrm{O}_{11} \mathrm{H}_{10}$ substrate cluster. The black curves refer to local spin density (LSDA) calculations while the lighter gray curves are results from calculations using generalized gradient (GGA) approximation. For a definition of $z(\mathrm{O}-\mathrm{H})$ and $z(\mathrm{Sub}-\mathrm{OH})$ see text. 


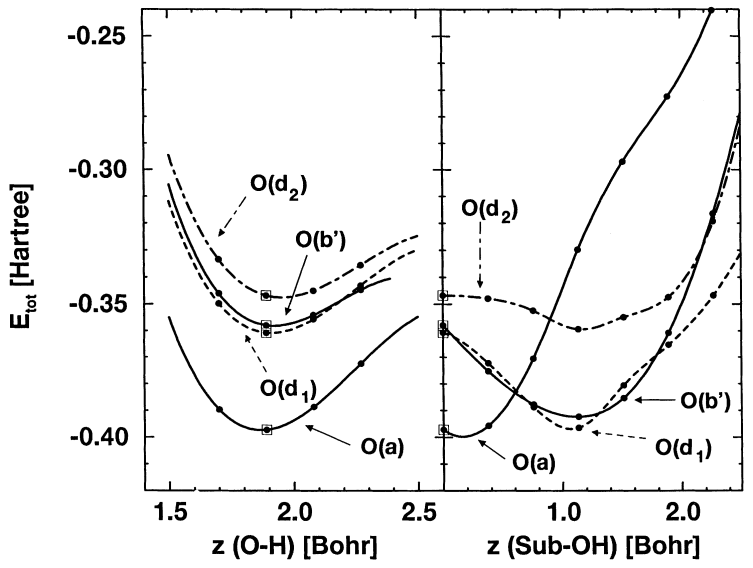

Fig. 6. Total energies $E_{\text {tot }}(z)$ as a function of the adsorbate distances $z$ for $\mathrm{H}^{+}$adsorption (left) and the $\mathrm{OH}$ desorption (right) at the $\mathrm{MoO}_{3}\left(\begin{array}{lll}1 & 0 & 0\end{array}\right)$ surface represented by the $\mathrm{Mo}_{3} \mathrm{O}_{12} \mathrm{H}_{6}$ substrate cluster. For a definition of $z(\mathrm{O}-\mathrm{H})$ and $z(\mathrm{Sub}-\mathrm{OH})$ see text.

two approaches. Thus, the curves of Fig. 6 are based on the LSDA scheme only.

Hydrogen is found to stabilize at all sites on both surfaces at similar distances $d(\mathrm{O}-\mathrm{H})$ close to the distance of free hydroxyl. Its rather strong binding, resulting in a local $\mathrm{OH}$ group, is determined by covalent as well as ionic contributions. The participation of ionic contributions to $\mathrm{O}-\mathrm{H}$ binding is confirmed by the electrostatic surface potential. Further, a comparison of Fig. 4(a) and (b) with Figs. 5 and 6 shows that terminal oxygen sites $\mathrm{O}(\mathrm{a})$ which lead to strongest binding are also sites where the electrostatic potential of the substrate cluster assumes its (negative) minimum. If, after stabilization of hydrogen at the surface, the local $\mathrm{OH}$ group is removed at different oxygen sites (simulated by total energy calculations on respective ( $\left.\mathrm{Mo}_{n} \mathrm{O}_{m-1} \mathrm{H}_{k}+\mathrm{OH}\right)$ clusters), the calculations reveal a qualitative difference between the different sites. The cluster total energy for the removal of $\mathrm{OH}$ involving the terminal oxygen $\mathrm{O}(\mathrm{a})$ exhibits a sharp minimum near the surface followed by a steep rise. This shows that the respective surface $\mathrm{OH}$ group is strongly bound to the underlying Mo metal center. In contrast, the total energy curves for $\mathrm{OH}$ removal involving bridging oxygens $\mathrm{O}\left(\mathrm{b}, \mathrm{b}^{\prime}\right)$ are rather shallow up to $1.5 \mathrm{Bohr}$ above the surface suggesting that respective surface $\mathrm{OH}$ groups can become quite mobile. These hydroxyls are therefore much more available for subsequent desorption and reaction than terminal $\mathrm{OH}$ groups. So the present model calculations may suggest that bridging oxygen sites rather than terminal ones participate in the selective oxidation of hydrocarbons at $\mathrm{MoO}_{3}$ surfaces [11]. It should be noted that the present model calculations assume a rigid substrate for $\mathrm{OH}$ desorption. Thus, possible surface relaxation and reconstruction (requiring an evaluation of rather complex multi-dimensional interaction potentials) are neglected and the present models can account only for initial desorption steps. However, these initial steps are believed to determine possible reaction channels which will also occur in a full treatment of the surface systems.

\subsection{Allyl oxidation at $\mathrm{MoO}_{3}\left(\begin{array}{lll}0 & 1 & 0\end{array}\right)$ and $\left(\begin{array}{lll}1 & 0 & 0\end{array}\right)$}

The oxidation of allyl $\left(\mathrm{CH}_{2}-\mathrm{CH}-\mathrm{CH}_{2}\right)$ to acrolein $\left(\mathrm{CH}_{2}=\mathrm{CH}-\mathrm{CHO}\right)$ at $\mathrm{MoO}_{3}$ substrates has been found experimentally to occur for $\left(\begin{array}{lll}0 & 1 & 0\end{array}\right)$ but not for $\left(\begin{array}{lll}1 & 0 & 0\end{array}\right)$ oriented surfaces [1]. It can be described by a concerted reaction where a hydrogen is removed from the allyl while a substrate oxygen is incorporated to yield acrolein. In a first attempt to study this reaction on a microscopic basis, and in particular, to understand its surface specificity, cluster calculations have been performed for the adsorption and surface binding of allyl at the $\mathrm{MoO}_{3}\left(\begin{array}{lll}0 & 1 & 0\end{array}\right)$ and $\left(\begin{array}{lll}1 & 0 & 0\end{array}\right)$ surfaces [7]. Here the local substrate environment near the surface is simulated by saturated $\mathrm{Mo}_{2} \mathrm{O}_{11} \mathrm{H}_{10}$ (for $\mathrm{MoO}_{3}\left(\begin{array}{lll}0 & 1 & 0\end{array}\right)$, see Fig. 2(d)) and $\mathrm{Mo}_{3} \mathrm{O}_{12} \mathrm{H}_{6}$ clusters (for $\mathrm{MoO}_{3}\left(\begin{array}{ll}1 & 0\end{array}\right)$, see Fig. 3(d)) to which the $\mathrm{C}_{3} \mathrm{H}_{5}$ adsorbate species is added. While the adsorbate geometry is taken from that of the free radical, the adsorbatesubstrate distance is optimized in DFT total energy calculations for stabilization above different surface oxygen sites and for different adsorbate orientations, shown in Figs. 7 and 8.

The allyl binding energies, obtained for the above clusters, are plotted as functions of the adsorbatesubstrate separation $z$ at the $\mathrm{MoO}_{3}\left(\begin{array}{lll}0 & 1 & 0\end{array}\right)$ and $\left(\begin{array}{lll}1 & 0 & 0\end{array}\right)$ surfaces in Figs. 9 and 10. Here $z$ refers to a perpendicular distance as indicated by arrows in the insets of the figures showing the different clusters, see also Figs. 7 and 8 . For both surface orientations the calculations yield a clearly preferred adsorbate geometry. On the $\mathrm{MoO}_{3}\left(\begin{array}{lll}0 & 1 & 0\end{array}\right)$ surface the allyl binds most strongly above an asymmetric bridging oxygen site, $\mathrm{O}(\mathrm{b})$, with the adsorbate plane perpendicular to the 
(1)

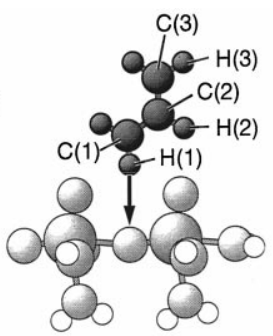

(3)

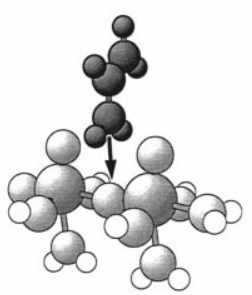

(2)

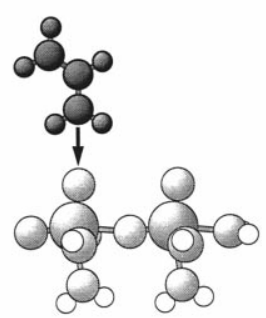

(4)

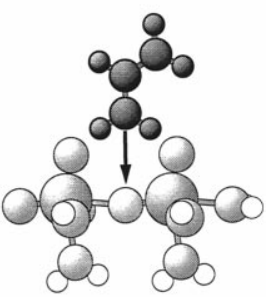

Fig. 7. Geometric details of allyl adsorbing at different oxygen sites of the $\mathrm{Mo}_{2} \mathrm{O}_{11} \mathrm{H}_{10}$ cluster modeling the $\mathrm{MoO}_{3}\left(\begin{array}{lll}0 & 1 & 0\end{array}\right)$ surface. The inequivalent carbon and hydrogen centers of the adsorbate are labeled accordingly.

(1)

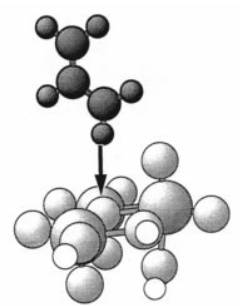

(3)

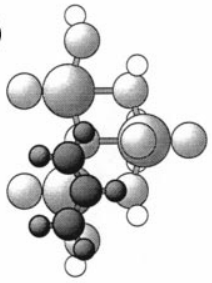

(2)

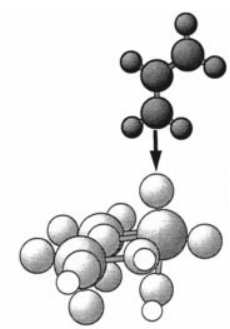

(4)

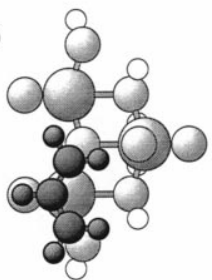

Fig. 8. Geometric details of allyl adsorbing at different oxygen sites of the $\mathrm{Mo}_{3} \mathrm{O}_{12} \mathrm{H}_{6}$ cluster modeling the $\mathrm{MoO}_{3}\left(\begin{array}{lll}1 & 0 & 0\end{array}\right)$ surface.

surface and one peripheral hydrogen, $\mathrm{H}(1)$, pointing towards the $\mathrm{O}(\mathrm{b})$ center, see geometry (1) of Fig. 7. On $\mathrm{MoO}_{3}\left(\begin{array}{lll}1 & 0 & 0\end{array}\right)$ the preferred adsorbate geometry is described by (3) of Fig. 8, where the allyl stabilizes above a bare metal center (these centers do not exist on $\left.\mathrm{MoO}_{3}\left(\begin{array}{lll}0 & 1 & 0\end{array}\right)\right)$ with its adsorbate plane parallel to the surface.

Table 3

Bond order differences $\Delta P$ due to adsorption in the $\mathrm{Mo}_{2} \mathrm{O}_{11} \mathrm{H}_{10^{-}}$ $\mathrm{C}_{3} \mathrm{H}_{5}$ cluster representing the $\mathrm{MoO}_{3}\left(\begin{array}{lll}0 & 1 & 0\end{array}\right)$ surface and adsorption geometry (1) of Fig. 7

\begin{tabular}{|c|c|c|}
\hline Bonds & $\Delta P\left(z_{\min }\right)$ & $\Delta P\left(z_{\text {red }}\right)$ \\
\hline \multicolumn{3}{|l|}{ Allyl } \\
\hline $\mathrm{C}(1)-\mathrm{C}(2)$ & -0.019 & -0.120 \\
\hline$C(2)-C(3)$ & -0.016 & +0.033 \\
\hline $\mathrm{C}(1)-\mathrm{H}(1)$ & -0.043 & -0.054 \\
\hline \multicolumn{3}{|l|}{$\mathrm{MoO}_{3}\left(\begin{array}{lll}0 & 1 & 0\end{array}\right)$} \\
\hline $\operatorname{Mo}(1)-O\left(a_{1}\right)$ & -0.049 & -0.090 \\
\hline $\mathrm{Mo}(2)-\mathrm{O}\left(\mathrm{a}_{2}\right)$ & -0.060 & -0.137 \\
\hline $\mathrm{Mo}(1)-\mathrm{O}(\mathrm{b})$ & +0.001 & -0.005 \\
\hline $\mathrm{Mo}(2)-\mathrm{O}(\mathrm{b})$ & -0.008 & -0.036 \\
\hline \multicolumn{3}{|c|}{ Allyl- $\mathrm{MoO}_{3}\left(\begin{array}{lll}0 & 1 & 0\end{array}\right)$} \\
\hline $\mathrm{C}(1)-\mathrm{O}\left(\mathrm{a}_{1}\right)$ & +0.019 & +0.033 \\
\hline $\mathrm{H}(1)-\mathrm{O}\left(\mathrm{a}_{2}\right)$ & +0.011 & +0.020 \\
\hline $\mathrm{H}(1)-\mathrm{O}(\mathrm{b})$ & +0.002 & +0.017 \\
\hline
\end{tabular}

The results are listed for the adsorbate-surface equilibium distance $z_{\min }$ and for $z_{\text {red }}=\left(z_{\min }-1\right)$ Bohr. Positive (negative) $\Delta P$ values correspond to the bond strengthening (weakening). All values are given in atomic units.

The differences $\Delta P$ in selected intra-adsorbate, intra-substrate and adsorbate-substrate bond orders in the surface clusters resulting from allyl adsorption are listed in Tables 3 and 4. The numerical results (negative $\Delta P$ values refer to adsorbate induced bond weakening, positive values to strengthening) are given for the energetically preferred adsorbate geometries, (1) for $\mathrm{MoO}_{3}\left(\begin{array}{lll}0 & 1 & 0\end{array}\right)$ (Table 3) and (3) for the $\mathrm{MoO}_{3}\left(\begin{array}{lll}1 & 0 & 0\end{array}\right)$ (Table 4), at equilibrium distance and also for an adsorbate-substrate distance decreased by 1 Bohr with respect to equilibrium. Here a comparison for different distances can give useful information about adsorbate-substrate bond formation when the adsorbate is approaching the surface. It is obvious from Figs. 9 and 10 that the calculations yield an overall rather weak interaction of the allyl adsorbate with both $\mathrm{MoO}_{3}$ surfaces together with unusually large equilibrium distances. This is most likely a consequence of the fixed adsorbate and substrate geometry used for the present models. Surface relaxation combined with adsorbate distortion may change the energetics and could even lead to completely new adsorption/reaction channels. Calculations along these lines require much larger clusters compared to those used in the present work and are out of reach 


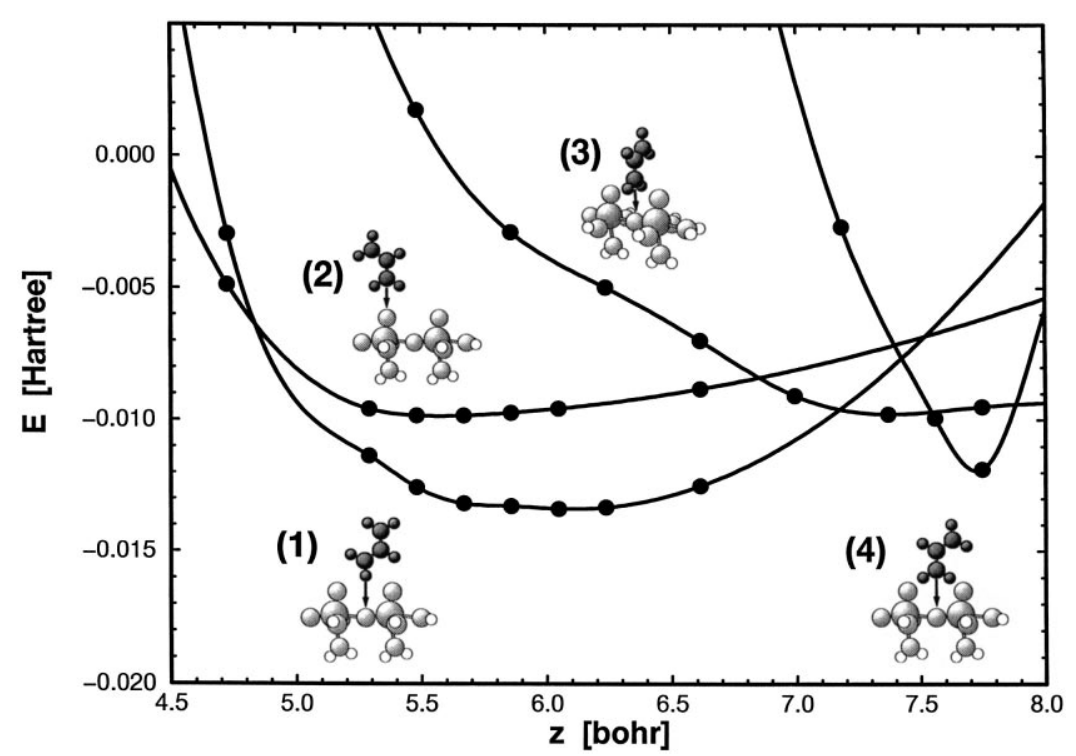

Fig. 9. Binding energy curves $E(z)$ of allyl adsorbing at different oxygen sites of $\mathrm{Mo}_{2} \mathrm{O}_{11} \mathrm{H}_{10}$ modeling the $\mathrm{MoO}_{3}(010)$ surface. For a definition of $z$ see text.

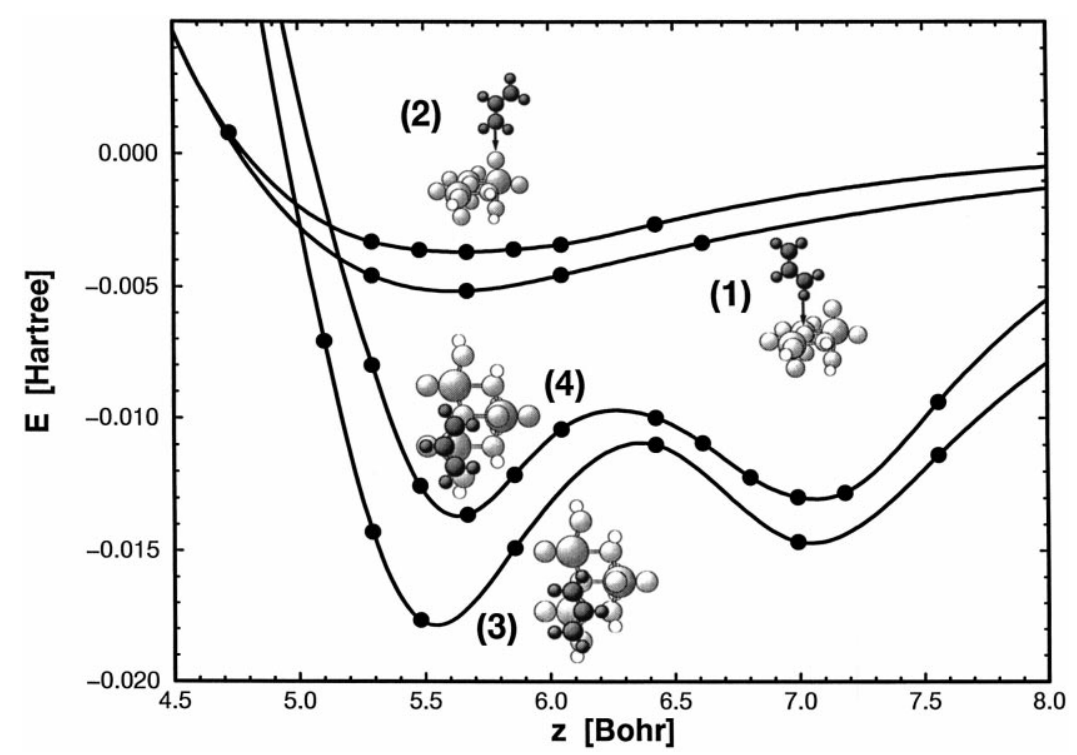

Fig. 10. Binding energy curves $E(z)$ of allyl adsorbing at different oxygen sites of $\mathrm{Mo}_{3} \mathrm{O}_{12} \mathrm{H}_{6}$ modeling the $\mathrm{MoO}_{3}(100)$ surface. For a definition of $z$ see text.

with present computational schemes. However, the present restricted models reveal already interesting details for the site dependent surface binding in the initial adsorption steps which can suggest possible mechanisms for the allyl to acrolein oxidation process [7].

On the $\mathrm{MoO}_{3}\left(\begin{array}{lll}0 & 1 & 0\end{array}\right)$ surface the adsorbate becomes most stable above an asymmetric bridging oxygen 
Table 4

Bond order differences $\Delta P$ due to adsorption in the $\mathrm{Mo}_{3} \mathrm{O}_{12} \mathrm{H}_{6}-$ $\mathrm{C}_{3} \mathrm{H}_{5}$ cluster representing the $\mathrm{MoO}_{3}\left(\begin{array}{lll}1 & 0 & 0\end{array}\right)$ surface and adsorption geometry (3) of Fig. 8

\begin{tabular}{|c|c|c|}
\hline Bonds & $\Delta P\left(z_{\min }\right)$ & $\Delta P\left(z_{\text {red }}\right)$ \\
\hline \multicolumn{3}{|l|}{ Allyl } \\
\hline $\mathrm{C}(1)-\mathrm{C}(2)$ & -0.096 & -0.124 \\
\hline$C(2)-C(3)$ & -0.090 & -0.124 \\
\hline $\mathrm{C}(1)-\mathrm{H}(1)$ & -0.040 & -0.043 \\
\hline $\mathrm{C}(1)-\mathrm{H}(2)$ & -0.073 & -0.096 \\
\hline \multicolumn{3}{|l|}{$\mathrm{MoO}_{3}\left(\begin{array}{lll}0 & 10\end{array}\right)$} \\
\hline $\mathrm{Mo}(1)-\mathrm{O}\left(\mathrm{b}^{\prime}\right)$ & -0.047 & -0.086 \\
\hline $\operatorname{Mo}(2)-O\left(b^{\prime}\right)$ & +0.000 & +0.001 \\
\hline $\mathrm{Mo}(2)-\mathrm{O}(\mathrm{a})$ & -0.093 & +0.103 \\
\hline \multicolumn{3}{|c|}{ Allyl-MoO $\mathrm{O}_{3}\left(\begin{array}{lll}1 & 0 & 0\end{array}\right)$} \\
\hline $\mathrm{C}(1)-\mathrm{Mo}(1)$ & +0.125 & +0.175 \\
\hline $\mathrm{C}(2)-\mathrm{Mo}(1)$ & +0.104 & +0.151 \\
\hline $\mathrm{C}(3)-\mathrm{Mo}(1)$ & +0.100 & +0.148 \\
\hline $\mathrm{C}(1)-\mathrm{O}\left(\mathrm{b}^{\prime}\right)$ & +0.000 & +0.008 \\
\hline $\mathrm{H}(1)-\mathrm{O}\left(\mathrm{b}_{2}^{\prime}\right)$ & +0.015 & +0.020 \\
\hline $\mathrm{H}(\mathrm{a})-\mathrm{O}\left(\mathrm{b}_{4}^{\prime}\right)$ & +0.022 & +0.031 \\
\hline
\end{tabular}

The results are listed for the adsorbate-surface equilibium distance $z_{\min }$ and for $z_{\text {red }}=\left(z_{\min }-1\right)$ Bohr. Positive (negative) $\Delta P$ values correspond to the bond strengthening (weakening). All values are given in atomic units.

site, $\mathrm{O}(\mathrm{b})$, where, however, due to the size of the adsorbate the two neighboring terminal oxygen sites, denoted $\mathrm{O}\left(\mathrm{a}_{1}\right)$ and $\mathrm{O}\left(\mathrm{a}_{2}\right)$, are also affected by the surface interaction, see geometry (1) Fig. 7. In this geometry, bond order analyses yield a slight weakening of all intra-allyl bonds accompanied by the formation of new partial $\mathrm{C}(1)-\mathrm{O}\left(\mathrm{a}_{1}\right), \mathrm{H}(1)-\mathrm{O}\left(\mathrm{a}_{1}\right)$, and $\mathrm{H}(1)-\mathrm{O}(\mathrm{b})$ bonds. A comparison of the results of the second and third column of Table 3 show that when allyl approaches the $\mathrm{MoO}_{3}\left(\begin{array}{lll}0 & 1 & 0\end{array}\right)$ surface all allylsubstrate bonds are strengthened. Further, the two C$\mathrm{C}$ bonds in the adsorbate become inequivalent with the $\mathrm{C}(1)-\mathrm{C}(2)$ bond weakening and the $\mathrm{C}(2)-\mathrm{C}(3)$ bond strengthening with decreasing adsorbate-substrate distance.

Similar conclusions about bond formation at the surface can be drawn from the charge density difference map shown in Fig. 11. Here electron density differences, shown as shaded contour plots, are obtained from a comparison of the adsorbate cluster result with that of a superposition of the isolated adsorbate and substrate cluster. Thus, Fig. 11 quanti- fies the electron charge rearrangement due to interaction between the allyl and the $\mathrm{MoO}_{3}$ substrate. Fig. 11(a) shows rather clearly a weak bond formation (accumulation of charge, positive charge density differences shown by full contour lines) between the allyl and the $\mathrm{MoO}_{3}\left(\begin{array}{lll}0 & 1 & 0\end{array}\right)$ surface in addition to the asymmetry in the two $\mathrm{C}-\mathrm{C}$ bonds in the adsorbate. Thus, the present calculations suggest an asymmetric electronic structure of the $\mathrm{C}_{3}$ skeleton of adsorbed allyl which is qualitatively similar to that in acrolein $(\mathrm{C}(1)-\mathrm{C}(2)$ single bond and $\mathrm{C}(2)-\mathrm{C}(3)$ double bond) and which can be interpreted as an initial step in the oxidation process.

On the $\mathrm{MoO}_{3}\left(\begin{array}{lll}1 & 0 & 0\end{array}\right)$ surface the allyl binds most strongly above a bare metal center with its adsorbate plane parallel to the surface, see geometry (3) of Fig. 8. As a result, the adsorbate-substrate coupling is dominated by bonds involving adsorbate $\pi$ and metal orbitals, cp. Table 4 and Fig. 11(b) and (c). Moreover, the calculations for geometry (3) give no indications of $\mathrm{O}-\mathrm{C}$ surface bond formation and there is no trend towards asymmetric $\mathrm{C}-\mathrm{C}$ bonds in the adsorbed allyl. Therefore, the results suggest that the allyl oxidation at the $\mathrm{MoO}_{3}\left(\begin{array}{lll}1 & 0 & 0\end{array}\right)$ surface is less likely to happen. Altogether, the present calculations give a rather simple geometric picture of the initial step of allyl to acrolein conversion at $\mathrm{MoO}_{3}$ based on the surface dependent binding character of the adsorbate which can explain the different results between the $\left(\begin{array}{lll}0 & 1 & 0\end{array}\right)$ and $\left(\begin{array}{lll}1 & 0 & 0\end{array}\right)$ surfaces found in the experiment.

\section{Conclusions}

The present cluster model calculations [4-7] yield electronic parameters which are well converged with respect to cluster size. Therefore, they can give a clear picture of the electronic structure and binding near the different oxygen sites at the different $\mathrm{MoO}_{3}$ surfaces, $\left(\begin{array}{lll}0 & 1 & 0\end{array}\right)$ and $\left(\begin{array}{lll}1 & 0 & 0\end{array}\right)$ oriented. The ionic nature of the $\mathrm{MoO}_{3}$ compound is confirmed by the calculations. Further, populations as well as bond orders show characteristic differences for geometrically inequivalent oxygen surface sites. Terminal molybdenyl oxygens accumulate the smallest negative charge $(-0.4)$ and their interaction with the environment is described by a double bond with the adjacent Mo center. Asym- 
(a)

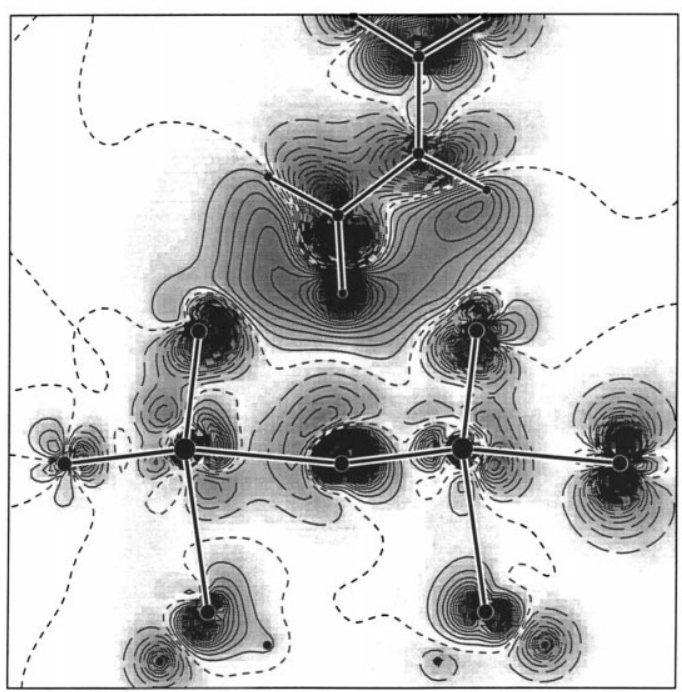

(b)

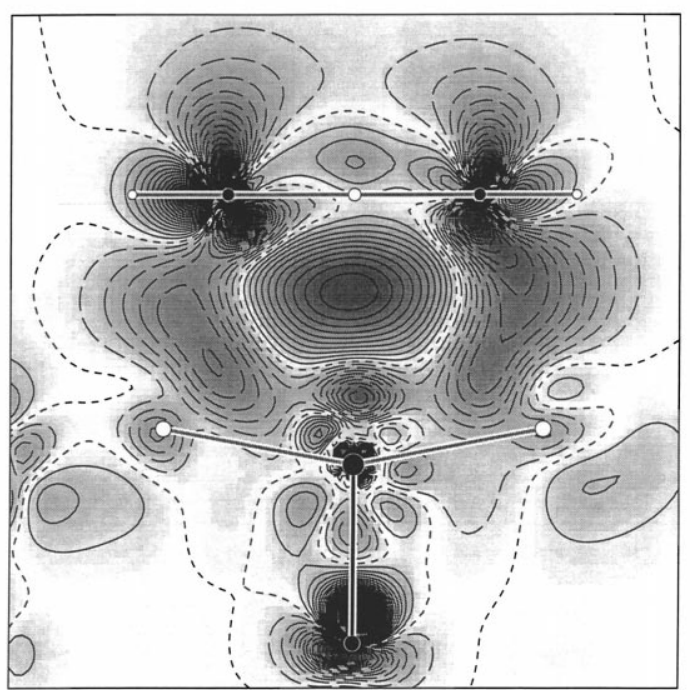

(c)

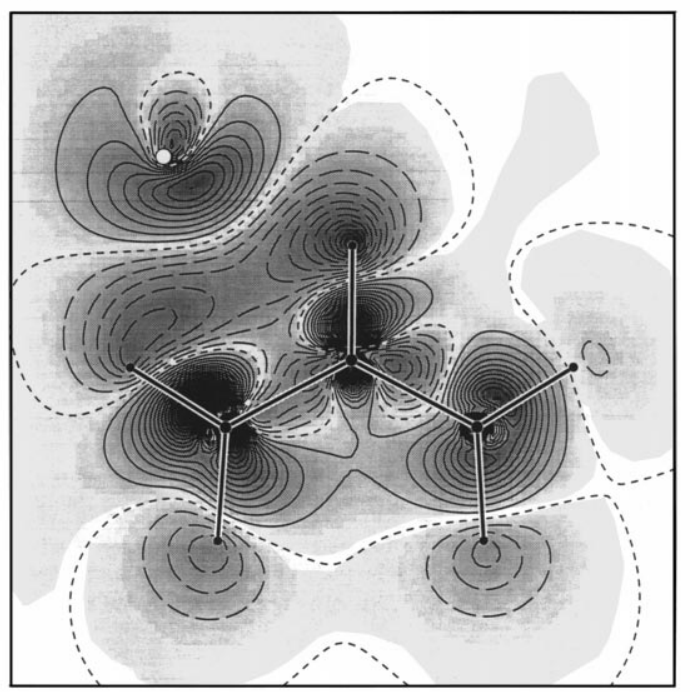

Fig. 11. Shaded contour plots of the charge density difference of: (a) $\mathrm{Mo}_{2} \mathrm{O}_{11} \mathrm{H}_{10}-\mathrm{C}_{3} \mathrm{H}_{5}$ referring to geometry (1) on $\mathrm{MoO}_{3}(010)$ for a cut perpendicular to the surface, (b) $\mathrm{Mo}_{3} \mathrm{O}_{12} \mathrm{H}_{6}-\mathrm{C}_{3} \mathrm{H}_{5}$ referring to geometry (3) on $\mathrm{MoO}_{3}\left(\begin{array}{ll}1 & 0\end{array}\right)$ for a cut perpendicular to the surface, and (c) $\mathrm{Mo}_{3} \mathrm{O}_{12} \mathrm{H}_{6}-\mathrm{C}_{3} \mathrm{H}_{5}$ as in (b) but for a cut along the allyl plane. Solid (dashed) contours correspond to positive (negative) values, with increments of 0.005 a.u.

metric bridging oxygens are slightly more negative $(-0.5)$ and characterized by a binding scheme similar to that for the molybdenyl oxygens. Symmetric bridging oxygens become most negative $(-0.8)$ and their binding behavior is described by single bonds with the two neighboring Mo centers. The cluster results obtained for geometrically equivalent oxygens at the $\mathrm{MoO}_{3}\left(\begin{array}{lll}0 & 1 & 0\end{array}\right)$ and $\left(\begin{array}{lll}1 & 0 & 0\end{array}\right)$ surfaces are found to be very similar and do not seem to depend strongly on the surface geometry. Therefore, the electronic structure at the two ideal surfaces is determined mainly by their detailed atom arrangement and is 
not influenced by major charge redistributions due to substrate surface binding.

Binding of hydrogen at the different oxygen sites of $\mathrm{MoO}_{3}$ results always in local surface $\mathrm{OH}$ groups and is determined by covalent as well as ionic contributions. Removal of $\mathrm{OH}$ from the surface after hydrogen adsorption proceeds differently depending on the surface oxygen site. Here, $\mathrm{OH}$ groups involving terminal oxygens $\mathrm{O}(\mathrm{a})$ are quite strongly bound to the surface and are thus unlikely to desorb. In contrast, hydroxyls involving bridging oxygens $\mathrm{O}\left(\mathrm{b}, \mathrm{b}^{\prime}\right)$ are more loosely coupled to the surface and mobile about the $\mathrm{H}$ adsorption minimum. Therefore, they are available for subsequent reactions and may desorb from the surface. So the present model calculations suggest that bridging oxygen sites rather than terminal ones participate in the selective oxidation of hydrocarbons at $\mathrm{MoO}_{3}$ surfaces.

As an example of more complex adsorbate-substrate binding the interaction of allyl with $\mathrm{MoO}_{3}\left(\begin{array}{lll}0 & 1 & 0\end{array}\right)$ and $\left(\begin{array}{lll}1 & 0 & 0\end{array}\right)$ surfaces is examined $[5,7,11]$. This interaction is found to be rather weak which may be, to a major extent, due to computational constraints assuming fixed adsorbate and substrate geometry. However, the calculations can give a simple qualitative picture based on the surface dependent binding character which suggests a starting point in the allyl to acrolein oxidation process on the $\left(\begin{array}{lll}0 & 1 & 0\end{array}\right)$ but not on the $\left(\begin{array}{lll}1 & 0 & 0\end{array}\right)$ surface. This confirms the experimental findings.

\section{Acknowledgements}

One of the authors (AM) gratefully acknowledges the Fellowship for Young Scientists from the Foundation for Polish Science. This work was funded in parts by the Deutsche Forschungsgemeinschaft and Fonds der Chemischen Industrie.

\section{References}

[1] E.R. Braithwaite, J. Haber (Eds.), Molybdenium: an outline of its chemistry and uses, Studies in Inorganic Chemistry, vol. 19, Elsevier, Amsterdam, 1994.

[2] J.C. Volta, J.L. Portefaix, Appl. Catal. 18 (1985) 1.

[3] J.C. Volta, J.M. Tatibouet, J. Catal. 93 (1985) 467.

[4] A. Michalak, K. Hermann, M. Witko, Surf. Sci. 366 (1996) 323.

[5] K. Hermann, M. Witko, A. Michalak, ACS-Symposium on Advances and Applications of Computational Chemical Modeling to Heterogeneous Catalysis, ACS Preprint, San Francisco, vol. 42, 1997, p. 106.

[6] K. Hermann, A. Michalak, M. Witko, Catal. Today 32 (1996) 321.

[7] A. Michalak, Ph.D. Thesis, Jagiellonian University, Cracow (Poland), 1996.

[8] L. Kihlborg, Arkiv Kemi 21 (1963) 357.

[9] A. Bielanski, J. Haber, in: Oxygen in Catalysis, Marcell Dekker, New York, 1991.

[10] J.K. Labanowski, J.W. Anzelm (Eds.), Density Functional Methods in Chemistry, Springer, New York, 1991.

[11] M. Witko, J. Mol. Catal. 70 (1991) 277. 